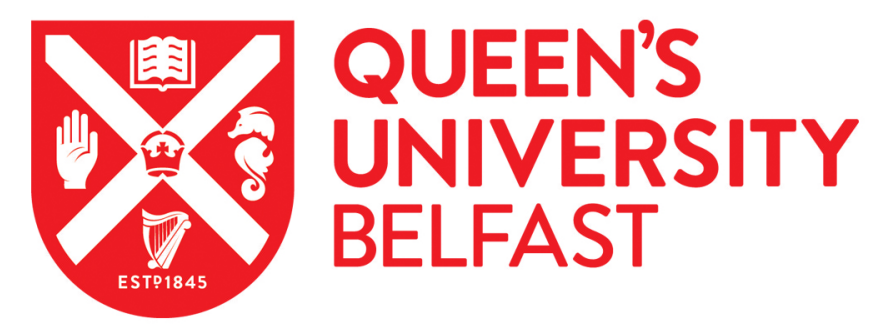

\title{
Learning through Practice: How Can We Address Loneliness among Older People?
}

Devine, P., Montgomery, L., Cowden, M., \& Murphy, F. (2020). Learning through Practice: How Can We Address Loneliness among Older People? Practice: Social Work in Action. https://doi.org/10.1080/09503153.2020.1727429

Published in:

Practice: Social Work in Action

Document Version:

Peer reviewed version

Queen's University Belfast - Research Portal:

Link to publication record in Queen's University Belfast Research Portal

Publisher rights

(c) 2020 British Association of Social Workers. This work is made available online in accordance with the publisher's policies. Please refer to any applicable terms of use of the publisher.

\section{General rights}

Copyright for the publications made accessible via the Queen's University Belfast Research Portal is retained by the author(s) and / or other copyright owners and it is a condition of accessing these publications that users recognise and abide by the legal requirements associated with these rights.

Take down policy

The Research Portal is Queen's institutional repository that provides access to Queen's research output. Every effort has been made to ensure that content in the Research Portal does not infringe any person's rights, or applicable UK laws. If you discover content in the Research Portal that you believe breaches copyright or violates any law, please contact openaccess@qub.ac.uk. 


\title{
LEARNING THROUGH PRACTICE: HOW CAN WE ADDRESS LONELINESS AMONG OLDER PEOPLE?
}

\author{
Paula Devine
}

ARK, School of Social Sciences, Education and Social Work, Queen's University Belfast ORCID https://orcid.org/0000-0002-8212-8619

@ark_info

Lorna Montgomery

School of Social Sciences, Education and Social Work, Queen's University Belfast ORCID https://orcid.org/0000-0003-0377-3773

Mandy Cowden

CLARE: Creative Local Action, Responses and Engagement

Fiona Murphy

Campaign to End Loneliness

Corresponding author: Paula Devine, p.devine@qub.ac.uk 
Dr Paula Devine is Co-director of ARK (www.ark.ac.uk), which is a joint initiative between Queen's University Belfast and Ulster University making social science information widely accessible to support civic society. She is based in the School of Social Sciences, Education and Social Work in Queen's University Belfast. Paula coordinates the ARK Ageing Programme, which supports knowledge engagement between the age, academic and policy sectors in Northern Ireland. She has been involved in the recording of public attitudes in Northern Ireland for over 20 years, and is director of the annual Northern Ireland Life and Times Survey. Her research interests include social attitudes; men's health; gender; social gerontology.

Dr Lorna Montgomery is a lecturer in Social Work at Queen's University Belfast, and is currently Director of Practice Learning for the social work degree. Prior to taking on this role, she practiced as a social worker in the areas of mental health and adult safeguarding and has worked in staff training in the health and social care sector. Her teaching and research interests include adult safeguarding, loneliness and isolation, bereavement care and mental health. She is also involved in research within family and child care social work and in particular in assessing parental capacity.

Mandy Cowden is a social worker with over twenty five experience in the statutory sector including a decade as a senior social worker in the Royal Victoria Hospital Belfast and more recently in the community sector. Seven years ago Mandy moved to a social work role within the Mount Vernon community to help engage in community based conversations with older people, drawing on lived experiences, that eventually led to the innovative CLARE CIC being established. Creative Local Action Responses and Engagement (CLARE) has now been delivering person centred early intervention support to isolated older people in North Belfast for six years. Initially Mandy developed the community social worker role in the project but has been the Project Manager for the last three years. She describes herself as a positive disrupter and is passionate about how social work can engage in community development and the need to design and collaborate across boundaries to make support systems accessible and meaningful to people who need them. 
Fiona Murphy has worked in a variety of roles with Civil Society and the Public Sector to create, innovate and implement positive change, particularly focused on social equity and human rights and currently leads the work of the Campaign to End Loneliness in NI. She specialises in participative practice and experiential learning with continuous improvement, creative programme development and project management at its core. Fiona uses the combined disciplines of research and policy, marketing, legal and values frameworks and education pedagogy to design bespoke interventions, establishing and supporting networks and using coaching and mentoring techniques to encourage committed, embedded, co-produced solutions. She has worked at an international, regional and national level including using UN mechanisms, EU and Council of Europe frameworks and national contexts including the Good Friday/Belfast Peace agreement. She has worked in Senegal, Jordan, Vietnam, Budapest, Switzerland, Turkey and Armenia and published articles on cross-border education work in Ireland and community development and social exclusion. Previously, Fiona setup and managed a human rights training programme spanning the Irish Civil and Public Services for the Irish Human Rights Commission.

Keywords: Loneliness, social isolation, older people, Northern Ireland, community development

Word count: 5984

No potential conflict of interest was reported by the authors. 


\title{
LEARNING THROUGH PRACTICE: HOW CAN WE ADDRESS LONELINESS AMONG OLDER PEOPLE?
}

\begin{abstract}
The rising incidence of loneliness and social isolation, especially among older people has increasingly been identified in research, practice and policy developments. These issues have become key concerns for public health and social care agendas. Although social isolation and loneliness are often conflated, they are not significantly correlated. The effects of loneliness and social isolation on physical, mental and emotional wellbeing are well documented. Addressing the causes and consequences of loneliness and social isolation is complex. This article outlines a practice example of a grassroots early intervention project seeking to alleviate loneliness and isolation in one community in Belfast, Northern Ireland. CLARE (Creative Local Action Responses and Engagement), a not for profit community interest company, provides a community-based response for isolated older people. The CLARE model encompasses community development worker roles and the skills of community social workers to support and grow community assets, including a vibrant volunteer base. CLARE demonstrates the effectiveness of a multi-dimensional model that addresses loneliness by encompassing three core areas of 'foundation services' as highlighted by the Campaign to End Loneliness. The strengths and challenges of these interventions, and their potential for addressing loneliness and social isolation are discussed.
\end{abstract}

\section{Introduction}

The rising incidence of loneliness and social isolation, especially among older people, has increasingly been identified in research, practice and policy developments. This has been matched with increasing coverage of the impact of loneliness and social isolation presented in the media. Reasons for this increase include lower levels of inter-generational living and greater social and 
geographical mobility (Valtorta and Hanratty 2010). This has led to an increased number of people living alone and at a distance from other family members. The risk of loneliness and social isolation is exacerbated by physical and mental ill health and lack of mobility. At the same time, changes to social and personal relationships and connections can be affected by our lifestyles, such as our use of technology and social media, or the amount of time we spend outside our home.

Social isolation and loneliness have become key concerns for public health and social care agendas. Addressing the causes and consequences of loneliness and social isolation is complex. This article outlines a practice example of a grassroots early intervention seeking to alleviate loneliness and isolation in one community in Belfast, Northern Ireland (NI). The article is based upon practical experience rather than theoretical study, as two of the authors are practitioners working in this field. (Author C is a Senior Social Worker with more than 20 years' experience working in the statutory sector and in community development. Author D has spent more than 20 years in advocating and campaigning roles seeking to influence key stakeholders to tackle and prevent loneliness).

This paper begins by outlining definitions and risk factors related to loneliness and social isolation. Policy initiatives to address associated problems are identified along with a discussion of effective approaches to reducing loneliness and isolation in later life. A case study is then given of a local coproduced community intervention model in Belfast. The paper concludes with a discussion of the strengths and challenges of these interventions, and their potential for addressing loneliness and social isolation. 


\section{Social isolation and loneliness}

Although social isolation and loneliness are often conflated they are not significantly correlated (Coyle and Dugan 2012). It is possible to be lonely without being socially isolated, to experience both loneliness and isolation, or to be socially isolated without feeling lonely (Valtorta and Hanratty 2010). Loneliness is a subjective state, and is defined as a negative emotion associated with a perceived gap between the quality and quantity of relations that an individual has, and what he or she may want (Perlman and Peplau 1981). Social loneliness relates to a perceived lack of wider social networks, whilst emotional loneliness focuses on the absence of a specific desired companion (Valtorta and Hanratty 2010). In contrast, social isolation is an objective state, characterised by a lack of social relationships and contacts. Accordingly, loneliness can be perceived as comprising the subjective component of social isolation. It is deeply personal and complex and is arguably a timeconsuming and multi-faceted issue for the health and social care sector.

The effects of loneliness and social isolation on physical, mental and emotional wellbeing are well documented, although the direction of causality is not definite, and the relationship with mediating factors is not always explicit. In their meta-analysis, Holt-Lunstad and colleagues (2015) found that people who were socially isolated, lonely or living alone were at a higher risk of mortality, regardless of age and other variables. Loneliness is also associated with a number of health risks including an increased risk of developing coronary heart disease and stroke (Valtorta et al. 2016).

Research by the Office for National Statistics (ONS) (2018a), based on data from the Community Life Survey carried out in 2016-17, found that 5\% of adults aged 16 of over in England felt lonely often or always. Higher rates were identified among women, younger adults (16-24 years), people who were widowed, those with poorer health, people with a long-term illness or disability, people 
who were unemployed, those people living alone, and people who felt less integrated within their neighbourhood. Harvey and Walsh (2016) indicated that members of LGBT community, people living with dementia or cognitive impairment, people with a physical disability, mobility issues or intellectual disability, carers; and people from ethnic minorities, are also at a particular risk of loneliness.

\section{Policy focus}

Loneliness and social isolation have become foci for lobbying, policy and research. However, Harvey and Walsh (2016) contend that the concept of social isolation is used more frequently than loneliness, perhaps because loneliness relates to emotions which may be perceived as not being a legitimate concern for the State. With increased awareness of the extent and effects of loneliness and isolation there have been a number of recent public and government policy developments across the United Kingdom (UK) and Ireland. For example, the Campaign to End Loneliness (CTEL), founded in 2010, is a UK-wide initiative seeking to promote evidence-based campaigning to commissioners, facilitate learning among organisations, build a research base, and support local initiatives to alleviate loneliness and social isolation.

Following this initiative, the Commission on Loneliness (a cross-party Commission of MPs and charities) was established by the late Jo Cox MP and ran until 2018. The resultant guidance 'Combating loneliness one conversation at a time' (Jo Cox Commission 2017) set out a number of strategies for combating loneliness. Whilst recognising that central government could not solve loneliness alone, it was seen as playing a pivotal role in galvanising the key players, catalysing 
action, assessing and comparing progress, and holding those who need to act accountable. In addition, catalysing action on the ground required government and other funders working together to support the development of innovative solutions to loneliness across all ages, backgrounds and communities. Integral to this is the need to help communities to develop self-sustaining activities which enable people to connect, scale-up and develop approaches to reach out to isolated lonely people, such as community navigators or social prescribing schemes. In order to assess measurable progress, there is a need for better data about who is affected by loneliness, and in what circumstances. This led to a proposal for a national indicator on loneliness across all ages with measures of loneliness included in major national studies, and annual reporting on loneliness by ONS. Parallel to this is the need to develop, collate and disseminate evidence on activities and interventions that help individuals connect with others.

Different approaches have developed across the UK. In England, the first strategy for tackling loneliness 'A connected society: a strategy for tackling loneliness - laying the foundations for change' (Department for Digital, Culture, Media and Sport 2018), sets out commitments from within government departments, as well as commitments to work with business, employers, local authorities, health and voluntary sector. The Scottish Government published its strategy in December 2018 'A Connected Scotland: Tackling social isolation and loneliness and building stronger social connections' with four clear priority areas (empower communities and build shared ownership, promote positive attitudes and tackle stigma, create opportunities for people to connect, and support an infrastructure that fosters connections). The 'Connected Communities consultation summary report' (2019), on tackling loneliness and isolation in Wales, re-affirms a commitment to prevention and early intervention. The Welsh Assembly have also appointed a research fellow to focus on interventions to address loneliness for older migrant and minority ethnic people in Wales. In NI, 
despite the Northern Ireland Assembly being in suspension since January 2017, MLAs have been discussing a NI strategy on loneliness, and Belfast City Council has passed a motion to encourage intergenerational and joined-up working on loneliness services.

In Ireland, the Loneliness Taskforce (2018) produced a set of recommendations for Government, state agencies and policy makers including the need to define loneliness based on qualitative and theoretical research, and to develop greater understanding of the impact of loneliness on health outcomes (for example, by analysing longitudinal or experimental studies). Recommendations also included the need to develop and pilot novel interventions, replicate intervention studies from other jurisdictions, develop further understanding of the impact of culture and lifespan on loneliness, and to take particular cognisance of the often transient and acute loneliness associated with widowhood.

\section{What works?}

The increased public and policy awareness of the effects of loneliness and social isolation brings with it an urgent need for evidence-based activities and interventions. 'The Promising Approaches to Reducing Isolation and Loneliness in Later Life' (Jopling, Campaign to End Loneliness and AgeUK 2015) provides a useful framework for understanding how to address loneliness, identifying varied solutions needed for an effective response to a very personal problem, whilst acknowledging that 'one size will not fit all'. This framework established that to be effective, the response to loneliness should take into account gateway services and barriers (such as transport and technology); provide direct interventions to provide connections to lonely older people and to address their practical and psychological needs; suggest how best to reach, identify and support older people; and 
take an approach that was community asset based, undertake neighbourhood approaches and encompass volunteering and positive ageing. CTEL have identified three core foundation services in addressing loneliness:

- reaching lonely individuals

- understanding the nature of an individual's loneliness and developing a personalised response

- $\quad$ supporting lonely individuals to access appropriate services.

Whilst various organisations have established different pathways to address these core challenges, this paper will focus on one such initiative in NI.

\section{The Northern Irish context}

With a population of 1.87 million (ONS 2018b) NI is experiencing demographic change, one driver of which is the increase in life expectancy. Between 2000 and 2017, the proportion of the NI population aged 65 and over grew from $13.1 \%$ to $16.2 \%$ (Northern Ireland Statistics and Research Agency, 2018).

NI is emerging from a 30-year history of civil conflict, the 'Troubles', with resultant economic, health and social issues (Gray et al 2018). In 1998, by which most of the paramilitary groups had stopped their armed struggle, devolved government was restored. However the NI Assembly was suspended in January 2017 and, at the time of writing, has not yet been reinstated. Concerns have been identified in relation to the continuing legacy of the Troubles on the population of NI, and the impact of health inequalities and austerity (Davidson and Leavey 2010; DHSSPS 2011; 2014; O'Connor et al. 2014). NI has relatively high levels of mental illness, including a $25 \%$ higher overall 
prevalence compared to England (DHSSPS 2014), and higher rates of suicide (https://www.assemblyresearchmatters.org/2019/02/27/suicide-statistics-and-policy-in-northernireland/). Despite these difficulties, NI spends less than half of England's per-capita spend on mental health problems and learning disabilities services (DHSSPS 2010).

There remains a strong political divide throughout NI, with residential and educational segregation, and evidence of ongoing prevalent sectarianism (Gray et al. 2018; Morrow 2019). However, community networks and relationships tend to be strong, and voluntary and community organisations represent a vibrant community which works alongside the statutory sector. Arguably the Peace Process has provided opportunities for bridging social capital to strengthen and develop networks and relationships (Leonard 2004).

\section{Combating loneliness and isolation in NI}

Policy developments are relevant to combating loneliness and isolation in Northern Ireland. In 2011, a Pensioners' Parliament was established in NI, seeking to identify and promote core issues of relevance to older people. The work of this group contributed to the establishment of a Commissioner for Older People who campaigned for a shift in attitudes to older people in which their contribution to society in terms of involvement in organisations, childcare, employment and sharing of skills and expertise has been increasingly recognised (Murtagh 2015). As outlined in its Active Ageing Strategy (Northern Ireland Executive 2016), NI is seeking to become an 'age friendly' society in which the diverse needs of differing ageing populations are promoted. Notably, the second Age Friendly Belfast Plan has been published (Belfast Strategic Partnership 2018). 
In addition, recent policy initiatives have promoted the home as the focus for health and social care provision (DHSSPS 2011; Thompson 2016). This is seen as an advantage to older people, who are more likely to wish to remain in their own homes as long as possible (NIHE 2013). To support this new direction, policy developments such as Caring for People Beyond Tomorrow (DHSSP 2005) and Transforming Your Care (DHSSPS 2011) have proposed a shift of service provision from hospital to community services (Thompson 2016). More recently, Power to People (Kelly and Kennedy 2016) identifies priority areas for the reform of adult social care in NI. These include the importance of prevention and early intervention as a means of reducing loneliness and the key role of community based innovative models of practice. One such model referenced was CLARE - a not for profit company established in North Belfast.

\section{CLARE}

For much of the population in North Belfast, poverty and health inequality remain key issues (Northern Ireland Assembly 2016). The area was deeply affected by the Troubles and is one of two constituencies with the highest average annual suicide rate in NI (http://www.assemblyresearchmatters.org/2016/09/16/death-by-suicide-in-northern-ireland/). There are high levels of residential segregation based on religion with the population split on an almost 50/50 Catholic/Protestant basis, with a small increase in people with more diverse identities moving into the area (Northern Ireland Housing Executive 2014). In 2014, 17\% of people of pensionable age (65 years for men and 60 years for women) were living alone (NIHE 2014). Despite, or maybe as a result of, these challenges a range of community assets were established. 
CLARE (Creative Local Action Responses and Engagement), is a not for profit community interest company established in 2013 with part funding from the Public Health Agency and a community social investment loan from Delivering Economic Renewal in Communities (DERiC). CLARE provides a community-based response for isolated older people living within North Belfast. It was founded as a result of action research to explore how community resources could meaningfully connect with older residents and create caring resilient communities, in the context of issues associated with poverty and the legacy of the Troubles. Key emerging issues from these initial oneto-one discussions with older people were loneliness, lack of family support or contact, complex physical and mental health issues, and the need for practical help to manage health care appointments and navigate support systems. This consultation identified health concerns related to loneliness and a social care system that was time, task and crisis driven and frequently not meeting the needs of older people.

This community-led organisation works in co-production with isolated older people to design and build personalised support that will fit the unique needs of individuals and help improve wellbeing. The CLARE model encompasses community development worker roles supporting and growing community assets, including a vibrant volunteer base and the skills of community social workers. The staff team consists of a Project Manager, a Community Volunteer Facilitator, two Community Social Workers, a Wellbeing Support Worker and an active team of Community Champion volunteers.

Referrals to CLARE are accepted from any source, although the majority come from the local 
Integrated Care Teams of the Health and Social Care Trust including specialist mental health and respiratory teams. Nevertheless, self-referrals of people aged 65 years or over who have little or no support networks and where wellbeing is being affected, are also encouraged. This group is often considered to be the most hard to reach.

Each person referred to CLARE meets with the Community Social Worker - usually over several visits - to talk about their unique life story, focussing on strengths and taking a co-production approach to what they are able to do and what barriers they face to living a more connected life. This creative conversation explores physical and mental wellbeing, mobility, finances, poverty and housing as well as levels of social care, support networks and aspirations for community involvement. A Living Plan is then agreed between the social worker and older person which identifies the services, resources and practical supports to enable the individual to maintain maximum independence, to promote choice and control, and to improve health and wellbeing. The Living Plan is flexible and can change according to the older person's circumstances and priorities. Importantly, CLARE does not have a set period or format of engagement; instead, it aims to be an easily accessible community resource, journeying with the person to provide community-based early intervention practice.

Outcomes of engaging with CLARE are measured in partnership with older people through seeking feedback, gathering stories and use of the Older Person's Star and Clarity IMS, (http://clarityims.org), a bespoke computer system designed through an innovative collaboration with CLARE staff and a computer company to help match and measure assets and record activity. Clarity $I M S$ is available to other community development organisations with the ambition of creating a 
shared community of users and as a fund-raising opportunity to support the work of CLARE. A recent review of a sample of Outcome Star measurements with older people accessing CLARE indicated an $85 \%$ increase in social connectedness and a $58 \%$ increase in sense of wellness.

\section{Case scenarios}

The following case scenarios of older people demonstrate the CLARE social worker's journey with the person to explore the practical and emotional impact of loneliness, bereavement and complex health issues, bringing the skill set of social work back into community-based early intervention practice. (Please note that pseudonyms have been utilised in the following examples).

\section{Anna}

Anna is 69 years old and lives alone. She has increasing mobility and sight challenges. Her accommodation is not suitable for her needs as she cannot manage the stairs. Although she was in receipt of statutory services and attended a Social Services Day Centre five days a week, Anna's circumstances were deteriorating. Her memory loss prompted a referral to the psychiatric services Memory Clinic. However, Anna did not respond to appointment letters and her referral was cancelled due to non-attendance. She was subsequently referred to CLARE.

The CLARE social worker got to know Anna over a number of visits and gained insights into how social isolation impacted Anna, identifying a range of other issues which arguably only the time and commitment to the professional relationship could reveal. The role of the social worker included liaising with other professionals, assisting with re-referral and attendance at the Memory Clinic, 
encouraging Anna to acknowledge and talk about an alcohol dependency which she attributed to her low mood and isolation, and addressing issues relating to debt. The social worker supported Anna to make the difficult decision to give up her driving licence as continuing to drive with eyesight problems was putting Anna and others at risk. In addition, the social worker helped Anna explore options for a move to sheltered accommodation which would be more suitable for her emotional, social and physical needs.

\section{Robert}

Robert is 75 years old. He was referred to CLARE from a community-based group because of concerns for his mental wellbeing and changes in his behaviour which began after his wife was diagnosed with dementia. Robert had become his wife's carer at home, but eventually had to make the difficult decision to seek a nursing home placement for her. He visited her daily.

Robert presented as angry; he could not accept the diagnosis of dementia and felt that he might still be able to 'fix' his wife. He tried counselling sessions in a generic counselling organisation but did not feel they were responsive to him as an older person. He then availed of a small innovative pilot counselling project: Talking Therapies at Home Service for older people. This is a partnership between CLARE and a trained counsellor, which enables older people to easily access counselling at home for eight weekly sessions. CLARE also facilitated referral to a psychologist-led transitional group for carers. Additionally, CLARE provided advice and support around the activities of daily living such as help to learn how to shop and cook. 


\section{Frank}

Frank is 72 years old and was initially referred to CLARE for help with his finances. Frank's communication and mobility had been affected by a stroke making him very isolated; he communicates by pointing to letters on a page to spell out words or by email. Frank had few friends and no family living in Northern Ireland. He had previously refused social services help with his daily care needs and the offer of day-centre attendance. CLARE has been assisting Frank to remain independent in a variety of ways: he has been linked to online banking, has been supported to attend his GP and other medical appointments, and has been able to relocate to more disability-friendly sheltered housing with help from joint working with a local housing organisation. Most significantly Frank has been able to access Direct Payments with support from CLARE, enabling him to employ someone to accompany him to local shops, thus providing social contact and a sense of independence.

\section{Discussion}

'The Promising Approaches to Reducing Isolation and Loneliness in Later Life' (Jopling, CTEL and AgeUK 2015) established a framework for understanding how to tackle the problems of isolation and loneliness, acknowledging that 'one size will not fit all'. The strength of this approach is in enabling a consistent framework by which a range of organisations can assess how they may impact on loneliness and, in particular, focus on the core policies, practices and services they should deliver. Importantly, this framework is of relevance to commissioners, funders and deliverers of services that support older people.

Arguably, this profile and case studies of CLARE demonstrate the effectiveness of a multidimensional approach to addressing loneliness by encompassing the three core areas of 'foundation 
services' identified by CTEL (CTEL, 2016): reaching those most isolated through community engagement and creative thinking; understanding the unique lived experience of the person referred; and addressing the impact of loneliness by having a range of means of supporting that are personalised to each person's circumstances.

\section{Reaching those most isolated through community engagement and creative thinking}

In working with socially isolated and lonely individuals in North Belfast, CLARE staff have recognised that loneliness and social isolation are not just issues at an individual level - services and interventions must encompass community and structural change. Thus, any developments in policy, practice or service provision relating to loneliness must be accompanied by wider social and cultural change which encourages self-efficacy, resilience, improved quality and quantity of connections and the destigmatisation of loneliness. The goal is ultimately to motivate empathy and compassion for the issue without cultivating 'pity' for older people and promoting negative social attitudes about loneliness.

It is also apparent that whilst CTEL focuses largely on the key roles and issues to be addressed by the public and third sectors, there is a significant role for employers and businesses to address loneliness either through their practices, products, services or assets. How to engage these organisations, shift their perceptions about their role for individuals and communities, and motivate change is yet to be clearly defined.

In reaching those most isolated through community engagement, CLARE also recognises the role of volunteering as an important consideration in community engagement. Effective and flexible 
methods of engaging and supporting volunteers are needed so that individuals are encouraged to donate resources, energy and time to the most effective forms of action and volunteering, which are often not explicit loneliness interventions. CLARE continue to encourage routes to employment for volunteers who gain skills, whilst challenging situations where roles are being assigned as volunteer status rather than paid employment.

\section{Understanding the unique lived experience of loneliness}

The experience of working closely with communities of diverse older individuals has given CLARE staff insights into the lived experiences of isolated and lonely older people. Thus, they have concluded that key to tackling loneliness is acknowledging the interactions of everyday life - how it feels to attend a GP or hospital appointment alone and have no one to discuss fears with; how essential tasks like accessing money or getting to the shops can seem impossible; and how someone receiving four visits per day from a homecare worker can still feel lonely. The case examples presented here identify some of the potential problems with routine service delivery; for example, Anna, with her sight and memory issues was discharged for non-attendance at a service as she did not respond to an appointment letter which she could neither see or understand. The generic counselling offered to Robert not meet his needs as an older male carer.

\section{Flexible and personal approaches to tackle loneliness}

Fundamentally, the CLARE scheme recognises the need for holistic, personalised, community based, preventative interventions as the core elements of effective practice. Innovations most likely to be effective at tackling loneliness were 'framed not as loneliness solutions, but as holistic and personcentred services, aimed at promoting healthy and active ageing, building resilience and supporting independence' (Jopling, CTEL and AgeUK 2015:12). CLARE have learnt from the older people they 
work with that encouraging social contact through group and one-to-one interactions and short-term re-engagement schemes is important, as promoted through the social prescribing agenda.

Nevertheless, more flexible approaches are needed. The lived experiences of Anna, Robert and Frank provide evidence that the approaches found to be most effective were those that were not just about reducing loneliness, but were holistic and person-centred.

Importantly, the CLARE initiative has provided insights into both community social work and sustainability. The CLARE scheme has adopted a deliberate focus on the re-engagement of radical social work within community development as a means of contributing to systemic change. This emphasises the importance of social work moving from assessment models and labelling to engaging holistically with people and their communities in a 'shift towards an alternative future that, ironically, has had a long and proud tradition in the not too distant past.' (Russell, Cormac. 2016, cited in Lyn Romeo 'Community social work: the shift from what's wrong to what's strong. Social work with adults Blog https://lynromeo.blog.gov.uk/2016/04/29/community-social-work-the-shiftfrom-whats-wrong-to-whats-strong/)

The CLARE model recognises that prevention and early intervention are essential; however, this is dependent on a paradigm shift in thinking around how the community is resourced and what power sharing and real partnership look like. Equity between statutory and third sector social workers, sharing functions and assessment roles need consideration. A return to authentic community social work requires a move away from crisis interventions. Community social work at its most basic level means to know the community where you work, such as its physical, social and health geography. It requires respecting the assets that exist within communities and the wider determinants of the health 
of the population engaged with. Social work is almost absent from early intervention community work, as navigators and sign posters and co-ordinators and connectors predominate.

However, essentially, as seen in the work with Anna, Robert and Frank, the community social worker has the resources to explicitly develop the relational aspects of the worker-client relationship. Through supported self-assessment, or guided conversation, each older person can agree their own pathway out of loneliness (Mortimer 2016; Jopling, CTEL and AgeUK 2015). Arguably this time commitment and relational focus, underpins the success of the service offered (Ruch 2018).

However, it must be acknowledged in the current climate of austerity that this is resource intensive. Murphy et al. (2013) explore the extent to which a relationship-based model can be truly personcentred, arguing that there is a mutual incompatibility of the person-centred approach brought about by the context and tasks of modern social work: 'In essence Social work is not person-centred; it is state-centred' (ibid, 717). However, the experience of the practitioners in the CLARE context would suggest that community-based grass-roots interventions have the potential to promote authentic person-centred practice.

\section{Sustainability and capacity building}

Finally, CLARE aims to address capacity building through community engagement, contributing to a community which is intentional and has capacity and capability in order to offer sustainable, interdependent and locality-based responses (Devine et al. 2017). CLARE has built links with existing community groups and advocates for funding to reach and sustain grassroots projects. There is an increasing interest among policy makers and commissioners in 'social prescribing', navigation and sign-posting as effective solutions to loneliness and isolation (Bickerdike et al. 2017). However, 
the reality of community-grown innovation is that funding streams are time limited, resulting in short-term projects and a trail of lost and abandoned projects, many of which had real potential to bring about meaningful change.

Investing in local communities can impact positively on health and wellbeing; local policies emphasise the importance of community-located early intervention supports and person-centred services linking across health and social care, community and statutory services. Demonstrating the effectiveness of prevention and early intervention and calculating savings to the system is a key challenge to securing funding away from the crisis end of interventions. There needs to be transparency, consistency and universal agreement on how to measure savings against a wide range of benefits (such as health improvement and local employment opportunities) and demonstrate prevention (SCIE, 2018). CLARE is currently undertaking a small pilot with the Health and Social Care Board and Belfast Health and Social Care Trust to further explore these challenges.

Arguably, CLARE's flexible community-based model is based on the premise that 'one size will not fit all'. From its inception CLARE has advocated for the need to reconfigure how health and social care systems are designed and delivered to be more prevention focussed, community grown and personalised to support older people to live well at home. Reclaiming a role for social work in community development was also seen as essential and innovative. This ethos concurs with a more recent review of adult social care which emphasised the need 'to make a fundamental shift away from a crisis dominated system to one of prevention based initially around people and their communities' (Kelly and Kennedy 2017, 46). The challenge for CLARE is how to offer the ethos and learning from this successful community-grown response to other communities, whilst 
recognising the diverse nature of communities within communities and the need for local ownership and buy in.

\section{References}

Belfast Strategic Partnership. 2018. Age Friendly Belfast Plan 2018 - 2021. Belfast: Belfast Strategic Partnership.

Bickerdike, Liz, Alison Booth, Paul M. Wilson, Kate Farley, and Kath Wright. 2017. "Social prescribing: less rhetoric and more reality. A systematic review of the evidence." BMJ Open 7:4e013384. doi:10.1136/bmjopen-2016-013384.

Coyle, Caitlin E., and Elizabeth Dugan. 2012. "Social isolation, loneliness and health among older adults." Journal of Aging and Health 24: 1346-1363. doi:10.1177/0898264312460275.

Davidson, Gavin, and Gerard Leavey. 2010. "Promoting mental health in Northern Ireland: addressing division, inequality and stigma." Journal of Public Mental Health 9 (4): 6-15.

Department for Digital, Culture, Media and Sport [DDCMS]. 2018. A connected society: a strategy for tackling loneliness - laying the foundations for change. London: DDCMS.

Department of Health, Social Services and Public Safety [DHSSPS]. 2005. Caring for People Beyond Tomorrow. Belfast: DHSSPS.

Devine, Paula, Lorna Montgomery, Janet Carter Anand, and Caoimhe Ní Dhónaill, Caoimhe. 2017. "Social isolation and older men - learning from research." Community Development Journal, 54: $273-289$.

Department of Health, Social Services, and Public Safety [DHSSPS] (2010). Reshaping the System: Implications for Northern Ireland's Health and Social Care Services of the 2010 Spending Review (McKinsey Report). Belfast: DHSSPS. 
DHSSPS. 2011. Transforming Your Care. Belfast: DHSSPS.

DHSSPS. 2014. Making Life Better. Belfast: DHSSPS.

Gray, Ann Marie, Jennifer Hamilton, Grainne Kelly, Brendan Lynn, Martin Melaugh, and Gillian Robinson. 2018. Northern Ireland Peace Monitoring Report, Number Five. Belfast Community Relationship Council.

Harvey, Brian, and Kathy Walsh. 2016. Loneliness and ageing: Ireland, North and South. Dublin: Institute for Public Health in Ireland.

Holt-Lunstad, Julianne, Timothy B. Smith, Mark Baker, Tyler Harris, and David Stephenson. 2015. "Loneliness and Social Isolation as Risk Factors for Mortality: A Meta-Analytic Review." Perspectives on Psychological Science 10: 227-237.

Jo Cox Commission on Loneliness. 2017. Combatting loneliness one conversation at a time. A call to action. Jo Cox Commission on Loneliness.

Jopling, Kate, Campaign to End Loneliness and AgeUK. 2015. Promising Approaches to Reducing Loneliness and Isolation in Later Life. London: Campaign to End Loneliness and AgeUK.

Kelly, Des, and John Kennedy. 2017. Power To People Proposals to reboot adult care and support in NI. Expert Advisory Panel on Adult Care and Support. Belfast: Department of Health.

Leonard, Madeleine, 2004. "Bonding and Bridging Social Capital: Reflections from Belfast." Sociology 38: 927-944.

Loneliness Taskforce. 2018. A Connected Island. An Ireland Free From Loneliness. A Report from the Loneliness Taskforce. Dublin: Loneliness Taskforce.

Morrow, Duncan. 2019. Sectarianism in Northern Ireland: A Review. Belfast: Ulster University. 
Mortimer, Jill. 2016. No one should have no one. Working to end loneliness amongst older people. London: AgeUK.

Murphy, David, Maria Duggan, and Stephen Joseph. (2013). "Relationship-based social work and its compatibility with the person-centred approach: Principled versus instrumental perspectives." The British Journal of Social Work 43 (4): 703-719. doi:10.1093/bjsw/bcs003

Murtagh, Brendan. 2014. "The politics of age in Northern Ireland." Generations: Journal of the American Society on Ageing 7: 72-78.

Northern Ireland Assembly. 2016. Constituency Profile. Belfast North - June 2016. Belfast: Northern Ireland Assembly.

Northern Ireland Executive. 2016. Active Ageing Strategy 2016-2026. Belfast: Northern Ireland Executive.

Northern Ireland Housing Executive [NIHE]. 2014. Inner North Belfast. Neighbourhood Renewal Survey. Belfast: NIHE.

Northern Ireland Housing Executive. 2013. Research on the Future Housing Aspirations of Older People. Belfast: NIHE.

Northern Ireland Statistics and Research Agency [NISRA]. 2018. 2017 Mid-year Population Estimates for Northern Ireland. Belfast: NISRA.

O’Connor, R.C., S. Rasmussen, and K. Hawton. 2014. “Adolescent self-harm: a school-based study in Northern Ireland." Journal of Affective Disorders 159: 46-52. doi: 10.1016/j.jad.2014.02.015

Office for National Statistics [ONS]. 2018a. Loneliness - What characteristics and circumstances are associated with feeling lonely?. London: ONS.

ONS. 2018b. Overview of the UK population: November 2018. London: ONS. 
Perlman, Daniel, and Letitia Anne Peplau. 1981. "Toward a Social Psychology of Loneliness". In Personal Relationships in Disorder, edited by N. Duck and R. Gilmour, 31-56. London: Academic Press.

Ruch, Gillian. 2018. "The Contemporary Context of Relationship based Practice". In Relationshipbased social work: Getting to the heart of practice, edited by Gillian Ruch, Danielle Turney, and Adrian Ward, 13-28. London: Jessica Kingsley Publishers.

Social Care Institute for Excellence [SCIE]. 2018. Tackling loneliness and social isolation: the role of commissioners. SCIE Highlights 3. Accessed 1 November 2019. https://www.scie.org.uk/prevention/connecting/loneliness-social-isolation/

The Scottish Government. 2018. A connected Scotland. Tackling social isolation and loneliness and building stronger social connections. Edinburgh: The Scottish Government.

Thompson, Janice. 2016. Transforming Health and Social Care in Northern Ireland - Services and Governance. Northern Ireland Assembly Research and Information Service Briefing Paper 40/16. Belfast: Northern Ireland Assembly Research and Information Service.

Valtorta, Nicole, and Barbara Hanratty. 2010. "Loneliness, isolation and the health of older adults: do we need a new health research agenda?" Journal of the Royal Society of Medicine 105: 518-522.

Valtorta, Nicole. K., Mona Kanaan, Simon Gilbody, Sara Ronzi and Barbara Hanratty, Simon Martin et al. 2016. 'Loneliness and social isolation as risk factors for coronary heart disease and stroke: systematic review and meta-analysis of longitudinal observational studies." Heart, 102: 1009-1016. doi:10.1136/heartjnl-2015-308790

Welsh Government. 2019. Connected Communities. Consultation - summary of responses. Cardiff: Welsh Government. 